\title{
EN DEFENSA DE LA CONCEPCIÓN EXPRESIVA DE LAS NORMAS*
}

\author{
Andrej Kristan** \\ Universidad de Girona \\ Universidad de Génova
}

RESUMEN. Frente a tres décadas de objeciones a la concepción expresiva de las normas, tal como fue presentada por ALCHOURRÓN y BULYGIN, el autor de este trabajo pretende demostrar, primero, que un expresivista que asumiera la propuesta de los dos maestros argentinos puede dar cuenta de los estados de cosas facultativos sin introducir incoherencias dentro del sistema normativo; segundo, que también puede describir con éxito el contenido proposicional de una metarregla sin dar contenido semántico al indicador de fuerza (normativa) de la regla-objeto; y tercero, que puede dar cuenta de una clausura permisiva aun cuando niegue la autonomía conceptual de los actos de permisión. A partir de estas demostraciones, el trabajo cierra sugiriendo una solución para una adecuada representación expresivista de las normas condicionales.

Palabras clave: teoría lógica de los sistemas normativos, reglas de preferencia, clausura permisiva, metarreglas, normas condicionales.

\section{In defence of the expressive conception of norms}

ABSTRACT. Against three decades of objections made to the expressive conception of norms as presented by ALCHOURRÓN and BULYGIN, the author of this paper purports to demonstrate, first, that their Expressivist accounts for facultative states of affairs without introducing inconsistencies into the normative system; second, that she can successfully describe the propositional content of a meta-rule without semanticizing the indicator of (normative) force of the object-rules; and third, that she can give an account of permissive closure even if she does not grant conceptual autonomy of acts of permitting. On the basis of these demonstrations, the author closes the paper with a suggestive solution for an adequate expressivist representation of conditional norms.

Keywords: logical theory of normative systems, rules of preference, permissive closure, meta-rules, conditional norms.

\footnotetext{
* Fecha de recepción: 31 de marzo de 2014. Fecha de aceptación: 22 de septiembre de 2014.

** Ante todo, quiero agradecer a Sebastián FIgUEROA RUBiO por su amable traducción de la penúltima versión de mi trabajo y a Beatriz PéReZ-Juste VALERo y Diego DeI VeCCHI por sus valiosas correcciones del texto final. Eventuales errores son míos.
} 


\section{LA APUESTA}

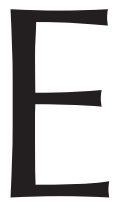

1 objetivo de «La concepción expresiva de las normas» (1981/1991a), escrito por AlChOURRÓn y Bulygin, era el de «explorar [las] posibilidades [de la concepción expresiva] para poner de manifiesto sus limitaciones y para mostrar de esta manera las diferencias» entre las concepciones hilética (o semántica) y la expresiva (o pragmática). Al final de su trabajo, llegan a la conclusión de que «las mismas distinciones conceptuales aparecen en ambas concepciones aunque — por supuesto- expresadas en lenguajes diferentes» (1991a: 127). Desde dicha publicación han surgido fuertes objeciones contra esta afirmación. En este trabajo me propongo revisar algunas de estas objeciones, tratando de afrontarlas desde los zapatos de un expresivista.

Específicamente consideraremos cinco objeciones ${ }^{1}$. En primer lugar se ha argumentado que la concepción expresiva, tal y como la construyen ALCHOURRÓN y BULYGIN, no puede dar cuenta de las permisiones fuertes o, al menos, de los estados de cosas facultativos $(\$ 2)$, sin introducir una contradicción dentro del sistema normativo $(\$ 3)$. Alternativamente, continúa el argumento, un expresivista que asuma esta posición tal como ellos la presentan no puede describir satisfactoriamente el contenido proposicional de las reglas de preferencia que se utilizan para resolver los conflictos de ambivalencia sin dotar de contenido semántico al indicador de fuerza elocutiva (normativa) (\$4). Esto último supondría asumir una concepción hilética. Por último, se ha señalado que un expresivista a la manera de ALCHOURRÓn y BULYGIN (1981/1991a) no puede dar cuenta de una regla de clausura permisiva si no asume antes que permitir es un acto normativo especial, diferente (y no reducible) al de ordenar, e incluso que no puede representar adecuadamente las normas condicionales $(\$ 5)$. En este artículo, sin embargo, intentaré demostrar lo contrario ${ }^{2}$. En los siguientes dos apartados espero aclarar, primero, la posición de los autores argentinos, proponiendo meramente unas formalizaciones de su concepción. La mayor parte de las definiciones introducidas allí no se utilizarán en los últimos dos apartados, donde propondré un posible desarrollo de la concepción expresiva. Esas definiciones servirán más bien para evitar la confusión y el mal entendimiento que, en mi opinión, explican en gran medida las objeciones mencionadas en el párrafo precedente.

\section{LAS DISTINCIONES FUNDAMENTALES}

Las dos grandes concepciones de las normas mencionadas en la introducción se parecen en cuanto ambas suponen que las «oraciones normativas» pueden ser analiza-

${ }^{1}$ Estas críticas se pueden encontrar en WEINBERgER, 1985 y 1986; NAVARRO y REDONDO, 1990a y 1990b; CALZETTA y SARDO, 2014. Vid. también en AlCHOURRÓn y BuLYGIN, 1991: xxvii, quienes concedieron un punto importante a WEINBERGER: la incapacidad del expresivista para ofrecer una reconstrucción satisfactoria de las normas condicionales en la lógica de proposiciones normativas. Se puede consultar CARACCIOLO, 1993: 507, para una mejor explicación de este punto.

2 Supongo que el lector estará familiarizado con las notaciones de la lógica clásica y de la teoría axiomática de conjuntos. Las notaciones en este trabajo seguirán el estándar ISO 31-11 (con la adición de $\Leftrightarrow$ para el conector bicondicional). Asumiremos todo el inventario habitual de la lógica clásica y de la teoría axiomática de conjuntos (si no se indica lo contrario), más tres axiomas que se introducirán más adelante. 
das en a) un componente descriptivo, de aquí en adelante llamado también el «contenido proposicional», que es la descripción de una acción o estado de cosas resultante de una acción, y b) el operador normativo. Las dos concepciones divergen en cómo analizan a este último elemento prescriptivo ${ }^{3}$.

\section{La concepción bilética considera al operador normativo}

como un signo en su capacidad semántica, de modo que este operador contribuye al significado semántico de las oraciones normativas, en cuyo caso una norma resulta ser el significado semántico de una oración normativa, de la misma manera como cabe decir de una proposición que es el significado (sentido) de una oración descriptiva ${ }^{4}$.

Así, una proposición descriptiva $p$ y un operador normativo «O» (para obligatorio), «Ph» (para prohibido) o «P» (para permitido) pertenecen ambos al contenido conceptual de la norma 5 .

La concepción expresiva, por otro lado, estima que el operador normativo

es un signo en capacidad pragmática, que no tiene ningún significado semántico y no forma parte del contenido conceptual de la oración normativa ${ }^{6}$.

Las normas, como tales, son actos del habla y no pueden ser negadas o formar combinaciones con la ayuda de los conectores proposicionales ${ }^{7}$. A los fines de una teoría lógica de los sistemas de normas, la fuerza elocutiva de una norma ha de ser representa$\mathrm{da}$, entonces, por medio de la pertenencia de su componente descriptivo a un conjunto.

Basado en este enfoque de la teoría de conjuntos, introducido por ALCHOURRÓN y BULYGIN (1981/1991a), un expresivista puede dar cuenta de las distinciones entre lo obligatorio, lo prohibido y lo permitido (ya sea de forma débil o fuerte). He aquí lo que apuntan al respecto:

$\ll p$ es obligatorio en $A »$ es verdadera si y sólo si, $p$ pertenece al sistema [normativo] $\operatorname{Cn}(A)$, es decir, si, y sólo si, $p$ pertenece a las consecuencias de $A$. Esto significa que $p$ es obligatorio en $A$ si, y sólo si, $p$ ha sido ordenado o es consecuencia de las proposiciones ordenadas. En este último caso decimos que [...] $p$ es una obligación derivada ${ }^{8}$.

Dado que el conjunto ordenado $A$ es, por definición, un subconjunto de $\operatorname{Cn}(A)$ :

Def. $1 \quad A \subseteq \operatorname{Cn}(A)$

su expresivista (de aquí en adelante: nuestro expresivista) puede distinguir las obligaciones derivadas de las explícitas, debido a que las primeras sólo figuran como miembros del conjunto $\mathrm{Cn}(A)$, mientras que las segundas figuran como miembros de ambos conjuntos, de la base axiomática $A$ y del sistema normativo $\operatorname{Cn}(A)$. Aunque una norma puede pertenecer a ambos conjuntos, los conceptos de norma derivada y de norma explícita se excluyen mutuamente:

Def. 2 Obligación $(\mathrm{O})$ :

$$
\forall p\left(\mathrm{O}_{A}(p) \Leftrightarrow p \in \operatorname{Cn}(A)\right) \text {. }
$$

3 Vid. Alchourrón y Bulygin, 1991a: 122-124; y 1991b: 156.

4 ALCHOURRÓN y BULYGIN, 1991b: 156. He omitido una nota a pie de página.

5 AlCHOURRÓN Y BuLYGIN, 1991a: 123.

6 AlChOURRÓN y BulYgin, 1991b: 156. He omitido una nota a pie de página.

7 Ibid., 157.

8 AlChOURRÓn y BulYgin, 1991a: 129. Los corchetes son míos. La identificación de la base axiomática del sistema con el conjunto $A$, y del sistema normativo con el conjunto $\operatorname{Cn}(A)$ se realiza en la misma página. 
Para todo $p, \ll p$ es obligatorio en $A »$ es verdadera si, y sólo si, $p$ pertenece al conjunto $\operatorname{Cn}(A)$.

Def. 3 Obligación explícita $(\mathbf{O})$ :

$\forall p\left(\mathbf{O}_{A}(p) \Leftrightarrow p \in A\right)$.

Para todo $p$, «p es explícitamente obligatorio en $A »$ es verdadera si, y sólo si, $p$ pertenece al conjunto $A$.

Def. 4 Obligación derivada (O):

$\forall p\left(\underline{\mathrm{O}}_{A}(p) \Leftrightarrow p \in \operatorname{Cn}(A) \wedge p \notin A\right)$.

Para todo $p$, «p es implícitamente obligatorio en $A \gg$ es verdadera si, y sólo si, $p$ pertenece al conjunto $\operatorname{Cn}(A)$ y no pertenece al subconjunto $A$.

De la misma forma, nuestro expresivista puede definir los conceptos de prohibición y permisión para proposiciones normativas (o estados de cosas).

Así, una proposición (o estado de cosas) $p$ está prohibida en $A$ si, y sólo si, su negación (o no- $p$ ) ha sido ordenada explícitamente o es una prohibición derivada, esto es, se trata de una consecuencia de las proposiciones que han sido ordenadas. Se puede formular lo mismo en términos de conjuntos: «p está prohibido en $A$ [si, y sólo si,] la negación de $p$ (no- $p$ ) pertenece al sistema [normativo] $\operatorname{Cn}(A) \gg{ }^{9}$, o tanto al sistema normativo $\operatorname{Cn}(A)$ como a su base axiomática, el conjunto ordenado $A$.

De esta forma, tal como en el caso de las obligaciones, nuestro expresivista puede distinguir las prohibiciones derivadas de las explícitas debido a que las probibiciones derivadas figuran solamente como miembros del conjunto $\mathrm{Cn}(A)$, mientras que las probibiciones explícitas figuran como miembros de ambos conjuntos, de la base axiomática $A$ y del sistema normativo $\operatorname{Cn}(A)$ :

Def. 5 Prohibición $(\mathrm{Ph})$ :

$\forall p\left(\mathrm{Ph}_{A}(p) \Leftrightarrow\right.$ no- $\left.p \in \operatorname{Cn}(A)\right)$.

Para todo $p$, «p está prohibido en $A \gg$ es verdadera si, y sólo si, no- $p$ pertenece al conjunto $\operatorname{Cn}(A)$.

Def. 6 Probibición explícita $(\mathbf{P h})$ :

$\forall p\left(\mathbf{P h}_{A}(p) \Leftrightarrow\right.$ no- $\left.p \in A\right)$.

Para todo $p$, «p está explícitamente prohibido en $A \gg$ es verdadera si, y sólo si, no- $p$ pertenece al conjunto $A$.

Def. 7 Probibición derivada $(\underline{\mathrm{Ph}})$ :

$\forall p\left(\underline{\mathrm{Ph}}_{A}(p) \Leftrightarrow\right.$ no- $p \in \overline{\mathrm{Cn}}(A) \wedge$ no- $\left.p \notin A\right)$.

Para todo $p$, «p está implícitamente prohibido en $A \gg$ es verdadera si, y sólo si, no- $p$ pertenece al conjunto $\operatorname{Cn}(A)$ y no pertenece al subconjunto $A$.

Una proposición (o estado de cosas) $p$ está permitida en $A$ si, y sólo si, su negación (no- $p$ ) no ha sido explícitamente ordenada y no es una prohibición derivada, esto es, si no se trata de una consecuencia de las proposiciones que han sido ordenadas. En términos de teoría de conjuntos: $p$ está permitido en $A$ si, y sólo si, «la negación de $p$ (no$p)$ no pertenece al sistema [normativo] $\mathrm{Cn}(A)_{\gg}{ }^{10}$. Una fórmula puede ser la siguiente:

\footnotetext{
9 Alchourrón y Bulygin, 1991a: 131.

${ }_{10}$ Ibid.
} 
Def. 8 Permiso (P):

$\forall p\left(\mathrm{P}_{A}(p) \Leftrightarrow\right.$ no- $\left.p \notin \operatorname{Cn}(A)\right)$.

Para todo $p$, «p está permitido en $A »$ es verdadera si, y sólo si, no- $p$ no pertenece al conjunto $\operatorname{Cn}(A)$.

Esto es válido tanto para los permisos débiles o negativos como para los fuertes o positivos (dado que las condiciones suficientes para la existencia de los primeros son condiciones necesarias para la de los segundos), pero no nos permite distinguir entre ellos. ¿Cómo podría el expresivista de ALCHOURRÓN y BULYGIN (1981/1991) distinguir entre ambos? Tal y como veremos a continuación, los autores enfrentan la cuestión directamente ${ }^{11}$.

Digamos que Rex permite $p$ al decir: «iPermito que se haga $p$ !» Nuestro expresivista puede analizar este acto del habla (al menos) de dos modos ${ }^{12}$. Puede describirlo como: a) el acto de rechazo de no- $p$ o como $b$ ) el acto de permitir $p$. Llamaré a la primera una reducción ockhamita y a la segunda un análisis moritziano ${ }^{13}$. En cualquiera de los casos, la proposición rechazada o permitida no puede ser incluida en el conjunto ordenado $A$, por dos razones obvias ${ }^{14}$ : i) primero, no podríamos distinguir los estados de cosas permitidos de los prohibidos si nuestra disposición es la de ponerlos todos juntos en un mismo conjunto, y ii) segundo, no haríamos más que introducir proposiciones contradictorias dentro del sistema normativo.

Para evitar estos problemas, ALCHOURRÓn y BULYGIN (1981/1991) proponen formar conjuntos separados: el derogandum o conjunto rechazado $D$ en el primer caso, y el conjunto permitido $P$ en el segundo ${ }^{15}$.

Un expresivista moritziano puede distinguir las proposiciones (o estados de cosas) fuertemente permitidas de las permitidas de forma débil en función de que solamente las primeras figuran como miembros del conjunto permitido $P$ :

Def. 9 Permiso fuerte $(\mathbf{P})$ :

$\forall p\left(\mathbf{P}_{A}(p) \Leftrightarrow p \in P\right)$.

Para todo $p$, «p está permitido de forma fuerte en $A \gg$ es verdadera si, y sólo si, $p$ forma parte del conjunto permitido $P$.

Def. 10 Permiso débil $(\underline{\mathrm{P}})$ :

$\forall p\left(\underline{\mathrm{P}}_{A}(p) \Leftrightarrow\right.$ no- $\left.p \notin \operatorname{Cn}(A) \wedge p \notin P\right)$.

Para todo $p, \ll p$ está permitido de forma débil en $A \gg$ es verdadera si, y sólo si, no- $p$ no pertenece al conjunto $\operatorname{Cn}(A)$ y $p$ no forma parte del conjunto $P$.

Desde la alternativa ockhamita se puede distinguir entre proposiciones (o estados de cosas) positivamente permitidas y aquellas negativamente permitidas debido a que solamente las negaciones de las primeras figuran como miembros del derogandum:

11 Alchourrón y Bulygin, 1991a: 131 y ss; 146 y ss.

12 Ibid., 146.

13 Moritz (1963) es el expresivista que admitió explícitamente que la naturaleza del acto del habla de permitir es diferente a la del de ordenar. Consecuentemente, admitió dos tipos de normas: normas imperativas (que establecen obligaciones y prohibiciones) y permisivas (que confieren poderes y permisos). El nombre de OСКНАM, por otra parte, sirve aquí para aludir al principio de parsimonia utilizado en la resolución de problemas (también conocido como la navaja de Ockham).

14 Respecto al acto de rechazo, vid. AlChOuRRón y Bulygin, 1991a: 132, para el de permisión AlCHOURRÓN y BULYGIN, 1991a: 148.

15 Ibid., 137 y 148. 
Def. 11 Permiso positivo $\left({ }^{+} \mathrm{P}\right)$ :

$\forall p\left({ }^{+} \mathrm{P}_{A}(p) \Leftrightarrow\right.$ no- $\left.p \in D\right)$.

Para todo $p$, «p está permitido de forma positiva en $A \gg$ es verdadera si, y sólo si, no-p forma parte del conjunto rechazado $D$.

Def. 12 Permiso negativo (-P):

$\forall p\left(-\mathrm{P}_{A}(p) \Leftrightarrow\right.$ no- $p \notin \mathrm{Cn}(A) \wedge$ no- $\left.p \notin D\right)$.

Para todo $p, \ll p$ está permitido de forma negativa en $A \gg$ es verdadera si, y sólo si, no-p no pertenece ni al conjunto $\operatorname{Cn}(A)$ ni al conjunto rechazado $D$.

Considerando cuanto se ha dicho, se pueden encontrar todas las distinciones fundamentales (obligaciones explícitas y derivadas, prohibiciones explícitas y derivadas, permisos débiles y fuertes) explicadas dentro de la concepción expresiva de las normas. QED ${ }^{16}$.

\section{FACULTATIVIDAD SIN CONTRADICCIÓN DENTRO DEL SISTEMA}

El hecho de trabajar con diferentes conjuntos (el conjunto ordenado $A$ por una parte, y el conjunto permitido $P$, y/o el derogandum $D$, por otra) nos protege de las contradicciones en caso de que haya estados de cosas facultativos. Esto puede demostrarse respondiendo a la siguiente pregunta: ¿qué efectos produce un acto de rechazo en el sistema normativo $\operatorname{Cn}(A) ?{ }^{17}$ o, alternativamente ${ }^{18}$ : ¿qué ocurre con $p$ como resultado de haber sido permitido? Trabajaremos con dos ejemplos.

3.1. Supongamos que Rex había ya dicho en una ocasión: «iPor la presente, les permito fumar!» y que $p$ representa la proposición <vosotros, fumar $>$. Podemos describir el acto de Rex como el acto de rechazo de no- $p$. Esto es una reducción ockhamita. Si no- $p$ no es un miembro del sistema normativo $\operatorname{Cn}(A)$ (fumar no ha sido explícitamente prohibido ni la prohibición de fumar es una consecuencia de otras proposiciones ordenadas), entonces $\operatorname{Cn}(A)$ se mantiene inalterado. Por otro lado, si no- $p$ fuese promulgada posteriormente, o si fuese una consecuencia de alguna proposición ordenada en el futuro, este hecho podría dar lugar a un «conflicto de ambivalencia» entre $\operatorname{Cn}(A)$ y $D^{19}$, que es un caso especial de lo que yo llamaría un conflicto de nocosostenibilidad:

Def. $13 \exists x(x \in \operatorname{Cn}(A) \wedge x \in D)$.

Existe al menos un $x$ tal que $x$ pertenece al conjunto $\operatorname{Cn}(A)$ y $x$ también pertenece al conjunto $D$.

Def. $14 \operatorname{Cn}(A) \cap D=\{x \mid x \in \operatorname{Cn}(A) \wedge x \in D\} \neq\{\varnothing\}$.

La intersección de $\operatorname{Cn}(A)$ con $D$ no es un conjunto vacío.

Def. $15 \operatorname{Cn}(A) \backslash D=\{x \mid x \in \operatorname{Cn}(A) \wedge x \notin D\} \neq \operatorname{Cn}(A)$.

La diferencia entre $\operatorname{Cn}(A)$ y $D$ - esto es, el conjunto de elementos que pertenecen a $\operatorname{Cn}(A)$ pero no a $D$ - no es igual a $\operatorname{Cn}(A)$.

\footnotetext{
16 Lat. Quod erat demonstrandum (esp. lo que se quería demostrar).

17 AlCHOURRón y Bulygin, 1991a: 138.

18 Ibid., 148.

19 Ibid., 136 y 138.
} 
Si deseamos un sistema normativo capaz de guiar la conducta efectivamente, es necesario que los conflictos de este tipo sean resueltos por medio de la aplicación de alguna regla de preferencia ${ }^{20}$, del mismo modo en que es necesario resolver el conflicto que acaece cuando es rechazada explícitamente una proposición que es miembro del sistema normativo $\operatorname{Cn}(A)$.

Si la proposición explícitamente rechazada no- $p$ es un miembro del sistema normativo $\operatorname{Cn}(A)$-esto es, si fumar ha sido prohibido, ya sea explícitamente, ya sea como consecuencia de otra proposición explícitamente ordenada posterior a que Rex dijese que «iPor la presente, les permito fumar!»-, entonces estamos ante un conflicto de ambivalencia y necesitamos una regla de preferencia para resolverlo. Si el conflicto se resuelve en favor del rechazo, entonces la proposición no- $p$ debe ser eliminada por sustracción tanto del conjunto ordenado $A$ como del sistema normativo $\operatorname{Cn}(A)$. Dicha sustracción, hace la proposición $\mathrm{O}_{A}($ no- $p$ ) falsa. Si el conflicto es resuelto en favor de la promulgación, entonces la proposición no- $p$ debe ser sustraída del conjunto rechazado $D$.

En el análisis alternativo de «iPor la presente, les permito fumar!» (el moritziano), podemos describir este acto de Rex como un acto de permitir. La proposición explícitamente permitida $p$ se agrega al conjunto permitido $P$ y aparece otro conflicto de no-cosostenibilidad entre $\operatorname{Cn}(A)$ y $P$ (levemente diferente al de la ambivalencia entre $\operatorname{Cn}(A)$ y $D)$ :

Def. $16 \exists x(x \in \operatorname{Cn}(A) \wedge$ no- $x \in P)$.

Existe al menos un $x$ tal que $x$ pertenece al conjunto $\operatorname{Cn}(A)$ y no- $x$ pertenece al conjunto $P$.

Def. $17 \operatorname{Cn}(A) \cap\{x \mid$ no- $x \in P\}=\{x \mid x \in \operatorname{Cn}(A) \wedge$ no- $x \in P\} \neq\{\varnothing\}$.

La intersección de $\operatorname{Cn}(A)$ con el conjunto de negaciones de los elementos de $P$ no es un conjunto vacío.

Def. $18\{x \mid x \in \operatorname{Cn}(A) \wedge$ no- $x \notin P\} \neq \operatorname{Cn}(A)$.

El conjunto de elementos de $\operatorname{Cn}(A)$ y las negaciones de lo que no pertenece a $P$ no es $\operatorname{Cn}(A)$.

Para resolver dicho conflicto ALCHOURRÓN y BULYGIN (1981/1991) nos invitan a aplicar las reglas de preferencia y, con ello, a sustraer $p$ del conjunto $P$ - si se da preferencia a la prohibición - o la negación de $p$ de los conjuntos $A$ y $\operatorname{Cn}(A)$ - si se prefiere a la permisión- ${ }^{21}$. A este respecto, la permisión de $p$ da lugar a la misma operación que el rechazo de no- $p$.

3.2. Supongamos que Rex también dice: «iPor la presente, les permito no fumar!». Esto es, existen dos pronunciamientos de autoridad: «iPor la presente, les permito fumar!» y «iPor la presente, les permito no fumar!». Siguiendo a WEINBERGER (1985), algunos temen que esto pueda introducir una contradicción en el sistema normativo $\operatorname{Cn}(A)^{22}$. Pero, si seguimos a AlChOURRÓN y BulYgin (1981/1991) no hay razón alguna para temerlo.

\footnotetext{
${ }^{20}$ Ibid., 136.

${ }^{21}$ Ibid., 148.

22 Vid. Weinberger, 1985: 173 y ss., y, recientemente, CalzetTa y SARdo, 2014: párr. 2.1.1.
} 
Como resultado del segundo pronunciamiento de Rex, el expresivista de ALCHOURRÓN y BULYGIN (1981/1991) añadirá $p$ al derogandum D o no- $p$ al conjunto permitido $P$. En el primer análisis, encontramos ahora en el derogandum $D$ tanto no- $p$ (debido al primer acto normativo de Rex) como $p$ (debido al segundo acto normativo de Rex); sin embargo, ni $p$ ni no- $p$ pertenecerán al sistema normativo $\operatorname{Cn}(A)$. Dentro del segundo análisis, el conjunto permitido $P$ se compone de dos elementos: $p$ y no- $p$ y, de nuevo, ninguno de los dos elementos es parte del sistema normativo $\operatorname{Cn}(A)$. Siguiendo ambos caminos, el mero hecho de que tanto fumar como no fumar esté permitido en el reino de Rex no genera una contradicción en el sistema normativo $\operatorname{Cn}(A)$ tal como lo describe nuestro expresivista ${ }^{23}$. QED.

Ahora bien, algunos quizás opinarán que mi respuesta no logra el objetivo porque seguimos teniendo a $p$ y no- $p$ en el conjunto derogado $D$. Hace un par de décadas NAVARRO y REDONDO (1990a) consideraron esto un problema. Su argumento (puesto con otras palabras) era el siguiente ${ }^{24}$ : de $p$ y no- $p$ todo se sigue, puesto que el conjunto de todas las consecuencias lógicas de $D$, esto es $\operatorname{Cn}(D)$, es omniincluyente. Consecuentemente, todos los elementos del conjunto ordenado $A$ y del sistema normativo $\operatorname{Cn}(A)$ deben ser eliminados por sustracción. Esto nos dejaría con los conjuntos $A$ y $\operatorname{Cn}(A)$ vacíos, lo cual es contraintuitivo y, en cualquier caso, altamente problemático.

De hecho, la conclusión es sensata. Pero, en mi opinión, el razonamiento que la sostiene va demasiado lejos. El expresivista de AlCHOURRón y BULYGIN (1981/1991) no tiene por qué operar con $\operatorname{Cn}(D)$ como conjunto de todas las consecuencias de $D$. Con el propósito de saber qué eliminar de $A$ y de $\operatorname{Cn}(A)$, nuestro expresivista tiene que identificar «todas las proposiciones y todos los conjuntos de proposiciones que implican alguna proposición que pertenece a $[D] \gg^{25}$. En otras palabras, necesita operar con proposiciones y conjuntos de los cuales los elementos de $D$ son consecuencia lógica y no viceversa ${ }^{26}$. El problema, por tanto, no existe.

Alguien podría acaso considerar contraintuitiva a la propuesta según la cual un expresivista en general ni necesita ni tiene razón alguna para trabajar con los conjuntos $\mathrm{Cn}(D)$ o $\mathrm{Cn}(P)$, pero no estoy al tanto de ningún desafío particular al respecto y, mientras nadie presente alguno, sólo se pueden añadir un par de cosas.

Uno podría pensar en dos rechazos, o en dos permisos, que (por vía de inferencia lógica) den lugar a un tercero. Sin embargo, los tipos de ejemplo que usualmente los escépticos presentan son inadecuados (conjeturo que esto se debe a que están influenciados por la concepción hilética) ${ }^{27}$. Supongamos que las siguientes dos reglas son promulgadas en el reino de Rex:

$\left(\mathbf{R}_{\mathbf{1}}\right)$ «Si está permitido hacer $\phi$, entonces está permitido hacer $\psi »$.

$\left(\mathbf{R}_{2}\right)$ «stá permitido hacer $\phi »$.

23 Siguiendo a ALCHOURRón y BulYgin, 1991a: 129, el sistema normativo ha sido definido como $\operatorname{Cn}(A)$ anteriormente en el apartado 2.

24 Vid. NAVARRO y REDONDO, 1990a: 251 y 254.

25 Alchourrón y Bulygin, 1991a: 138.

26 ALCHOURRón y BulYgin, 1979: 91-92.

27 Vid., al menos, ibid., Cap. 8, donde la representación formal de normas condicionales en la concepción expresiva se realiza en términos hiléticos: si $p$, entonces [es ordenado] $q$. Se afrontará este problema en el apartado 5 . 
Estas dos reglas originan:

$\left(\mathbf{R}_{3}\right) \quad$ Está permitido hacer $\psi$.

No obstante, en contraste con un análisis hilético, el expresivista analizaría $R_{1}$ como una orden y no como un permiso. El contenido proposicional de $\mathrm{R}_{1}$ (que aún debe en rigor de verdad precisarse pero que para el presente propósito puede suponerse como si fuere: si $p$, entonces $q$ ) aparecerá, consecuentemente, en la base axiomática $A^{28}$. El contenido proposicional de $\mathrm{R}_{2}$ (esto es, $p$ ) aparecerá en el conjunto permitido $P$ (o, en la alternativa ockhamita, su negación aparecerá en el derogandum D). Así, la introducción de $q$ en $P$ (o la introducción de no- $q$ en $D$ ) no es una consecuencia lógica de dos elementos de $P$ (o de dos elementos de $D$ ); se trata de una consecuencia lógica de un elemento de $A$ y de un elemento de $P$ (o $D$ ). En fin, de este ejemplo no se sigue en absoluto la necesidad de trabajar con $\operatorname{Cn}(P)$ o con $\operatorname{Cn}(D)$ para poder explicar la introducción de $q$ en $P$ (o de no- $q$ en $D$ ).

En este momento es importante recalcar que la introducción de un contenido proposicional en un conjunto o su eliminación del mismo, no es más que una metáfora. Un contenido que no pertenece a un conjunto, no comenzará nunca a formar parte de él. $\mathrm{Y}$ si un contenido pertenece a un conjunto, nunca dejará de formar parte de él ${ }^{29}$. Lo que realmente ocurre es la realización de un acto del habla (el ordenar, el prohibir; el permitir, si se quiere), que es un hecho empírico. Cada vez que un nuevo hecho acaece, tenemos nuevas descripciones del mundo en términos de conjuntos. De este modo, en el transcurso del tiempo no tenemos uno, sino varios conjuntos $\left[A_{1}, A_{2}, \ldots A_{n} ; \operatorname{Cn}\left(A_{1}\right)\right.$, $\left.\operatorname{Cn}\left(A_{2}\right), \ldots \operatorname{Cn}\left(A_{n}\right) ; D_{1}, D_{2}, \ldots D_{n} ; P_{1}, P_{2}, \ldots P_{n}\right]$. Siguiendo esta propuesta de AlCHOURRÓN y BulYGin (1981/1991), un conjunto consecutivo $A, D$ o $P$ siempre puede ser definido en relación con los conjuntos previos del mismo tipo y el contenido proposicional que es objeto del nuevo acto del habla. Si utilizamos los signos «! $\langle$, «i y «"*» para indicar el tipo de acto del habla normativo realizado (orden, rechazo, permiso) y «p» para su contenido proposicional, entonces podemos representar como sigue tres axiomas (adicionales) de una teoría expresiva, axiomas que no han sido explícitamente formulados por los autores:

Axioma $1 \quad \forall p\left(\left(! p \Rightarrow\left(A_{n}=\{p\} \cup A_{n-1}\right) \wedge\left(D_{n}=D_{n-1}\right) \wedge\left(P_{n}=P_{n-1}\right)\right)\right.$.

Para todo $p$, si $p$ acaba de ser ordenado, entonces el nuevo conjunto $A_{n}$ está formado por $p$ y todos los elementos del conjunto previo $A_{n-1}$, mientras que los nuevos conjuntos $D_{n}$ y $P_{n}$ se mantienen iguales a los conjuntos $D_{n-1}$ y $P_{n-1}$, respectivamente.

Axioma $2 \forall p\left(\left(; p \Rightarrow\left(D_{n}=\{p\} \cup D_{n-1}\right) \wedge\left(A_{n}=A_{n-1}\right) \wedge\left(P_{n}=P_{n-1}\right)\right)\right.$.

Para todo $p$, si $p$ acaba de ser rechazado, entonces el nuevo conjunto $D_{n}$ está formado por $p$ y todos los elementos del conjunto previo $D_{n-1}$, mientras que los nuevos conjuntos $A_{n}$ y $P_{n}$ se mantienen iguales a los conjuntos $A_{n-1}$ y $P_{n-1}$, respectivamente.

Axioma $3 \forall p\left(\left({ }^{*} p \Rightarrow\left(P_{n}=\{p\} \cup P_{n-1}\right) \wedge\left(A_{n}=A_{n-1}\right) \wedge\left(D_{n}=D_{n-1}\right)\right)\right.$.

Para todo $p$, si $p$ acaba de ser permitido, entonces el nuevo conjunto $P_{n}$ está formado por $p$ y todos los elementos del conjunto previo $P_{n-1}$,

28 Para los propósitos de esta sección no es necesario dar mayor detalle sobre la reconstrucción del contenido proposicional de las normas condicionales. Como se señala en la nota anterior, a este tema me referiré más adelante.

29 Vid. Alchourrón y Bulygin, 1991a: 134. 
mientras que los nuevos conjuntos $A_{n}$ y $D_{n}$ se mantienen iguales a los conjuntos $A_{n-1}$ y $D_{n-1}$, respectivamente.

El sistema normativo $\operatorname{Cn}(A)$, por otra parte, es simplemente el conjunto de todas las consecuencias lógicas de $A_{n}$-tal y como, de forma explícita, ha sido definido por ALCHOURRÓN y BULYGIN ${ }^{30}$ -

\section{EL CONTENIDO PROPOSICIONAL DE REGLAS SOBRE REGLAS}

Es natural considerar a las reglas de preferencia como metarreglas. Entonces, la cuestión es cómo puede un expresivista representar el contenido proposicional de tales metarreglas sin dotar de contenido semántico al indicador de la fuerza elocutiva (normativa) de las reglas-objeto ( $c f r$. WeINBERGER, 1985: 175; CALZETTA y SARDO, 2014: párr. 2.2). Una solución elegante es representar el contenido proposicional de la metarregla como operando no sobre reglas-objeto, sino sobre conjuntos que contengan (explícita o implícitamente) tal contenido proposicional. Estos conjuntos son el conjunto ordenado $A_{n}$, el conjunto rechazado $D_{n}$, el conjunto permitido $P_{n}$ y el sistema normativo $\operatorname{Cn}(A)$.

El contenido proposicional, digamos $w$, de la regla de preferencia (!w), usualmente conocida como lex posterior priori derogat ${ }^{31}$, podría representarse en una conjunción de condicionales a efectos de que los conjuntos consecutivos no incluyan aquellos contenidos proposicionales de oraciones normativas previas (o aquellas de sus consecuencias) que en relación con los más recientes producen algún conflicto ${ }^{32}$ :

Def. 19 El contenido proposicional de lex posterior $(w)$.

$\forall x\left[\left(x \notin D_{n-1} \wedge x \in D_{n}\right) \vee\left(\right.\right.$ no- $x \notin P_{n-1} \wedge$ no- $\left.x \in P_{n}\right) \wedge\left(x \in \operatorname{Cn}\left(A_{n-1}\right) \wedge x\right.$ $\left.\in \operatorname{Cn}\left(A_{n}\right)\right)$;

$\left.\Rightarrow\left(D_{n+1}=D_{n}\right) \vee\left(P_{n+1}=P_{n}\right) \wedge\left(\operatorname{Cn}\left(A_{n+1}\right)=\operatorname{Cn}\left(A_{n}\right) \backslash\{x\}\right) \wedge\left(A_{n+1}=A_{n} \backslash\{x\}\right)\right]$. $\wedge\left[\left(x \in D_{n-1} \wedge x \in D_{n}\right) \vee\left(\right.\right.$ no- $x \in P_{n-1} \wedge$ no- $\left.x \in P_{n}\right) \wedge\left(x \notin \operatorname{Cn}\left(A_{n-1}\right) \wedge x \in\right.$ $\left.\operatorname{Cn}\left(A_{n}\right)\right)$;

$\Rightarrow\left(D_{n+1}=\left(D_{n} \backslash\{x\}\right)\right) \vee\left(P_{n+1}=\left(P_{n} \backslash\{\right.\right.$ no- $\left.\left.x\}\right)\right) \wedge\left(\operatorname{Cn}\left(A_{n+1}\right)=\operatorname{Cn}\left(A_{n}\right)\right) \wedge$ $\left.\left(A_{n+1}=A_{n}\right)\right]$

$\wedge\left[\left(x \notin \operatorname{Cn}\left(A_{n-1}\right) \wedge x \in \operatorname{Cn}\left(A_{n}\right)\right) \wedge\left(\right.\right.$ no- $x \in \operatorname{Cn}\left(A_{n-1}\right) \wedge$ no- $\left.x \in \operatorname{Cn}\left(A_{n}\right)\right)$. $\Rightarrow\left(\operatorname{Cn}\left(A_{n+1}\right)=\left(\operatorname{Cn}\left(A_{n}\right) \backslash\{\right.\right.$ no-x $\left.\}\right) \wedge\left(A_{n+1}=\left(A_{n} \backslash\{\right.\right.$ no- $\left.\left.\left.\left.x\}\right)\right)\right)\right]$.

$\wedge\left[\left(\left(x \in \operatorname{Cn}\left(A_{n-1}\right) \wedge x \in \operatorname{Cn}\left(A_{n}\right)\right) \wedge\left(\right.\right.\right.$ no $-x \notin \operatorname{Cn}\left(A_{n-1}\right) \wedge\left(\right.$ no $\left.-x \in \operatorname{Cn}\left(A_{n}\right)\right)$.

$\Rightarrow\left(\operatorname{Cn}\left(A_{n+1}\right)=\left(\operatorname{Cn}\left(A_{n}\right) \backslash\{x\}\right) \wedge\left(A_{n+1}=\left(A_{n} \backslash\{x\}\right)\right)\right]$.

Para todo $x$, si $x$ acaba de ser rechazado (o no- $x$ permitido), siendo miembro de un sistema normativo $\mathrm{Cn}(A)$, entonces los nuevos conjuntos $A$ y $\operatorname{Cn}(A)$ están compuestos por todos los elementos de los conjuntos previos, excepto $x$, mientras que el conjunto $D$ (o el nuevo conjunto $P$ ) se mantiene igual al previo;

30 Vid. la definición 1, dada en el apartado 2. Vid. también ALCHOURRÓn y BuLYGIN, 1991a: 129.

31 Si seguimos la terminología de ALCHOURRÓN y BULYGIN, 1991a: 136, cuyo expresivista distingue lo que denominan lex posterior de lo que denominan auctoritas posterior, esta regla correspondería a lex posterior \& auctoritas posterior. He decidido dar una representación formal unitaria por cuestiones de simplicidad, aunque ambas reglas pueden separarse fácilmente.

32 La representación sirve a ambos tipos de expresivistas (ockhamitas y moritzianos). Para los ockhamitas el conjunto $P$ siempre será un conjunto vacío. 
- y si $x$ acaba de ser ordenado, siendo miembro del conjunto $D$ (o no- $x$ un miembro del conjunto $P$ ), entonces el nuevo conjunto $D$ está compuesto por todos los elementos de los conjuntos previos, excepto $x$, (o el nuevo conjunto $P$ está compuesto por todos los elementos de los conjuntos previos, excepto no- $x$,), mientras que los nuevos conjuntos $\mathrm{A}$ y $\operatorname{Cn}(A)$ se mantienen igual a los previos;

- y si $x$ acaba de convertirse en un miembro del sistema normativo, siendo no- $x$ también miembro del sistema normativo, entonces los nuevos conjuntos $\mathrm{A}$ y $\mathrm{Cn}(A)$ están compuestos por todos los elementos de los conjuntos previos, excepto no- $x$;

- y si no- $x$ acaba de convertirse en un miembro del sistema normativo, siendo $x$ también miembro del sistema normativo, entonces los nuevos conjuntos $A$ y $\operatorname{Cn}(A)$ están compuestos por todos los elementos de los conjuntos previos, excepto $x$.

Cuando Rex realiza $! w$, la proposición $w$ pasa a ser miembro del conjunto ordenado $A$. Como veremos, esto garantiza la preferencia de un acto normativo posterior (más allá de si este es una promulgación o un rechazo o, incluso, un permiso en caso de aceptar el análisis moritziano) sobre los anteriores.

Consideremos, por ejemplo, que Rex comienza su reinado con el sistema del fallecido Rex-Padre en el cual hay una (y sólo una) prohibición (no-p):

(t1) «iNo tocarás lo que es propiedad del rey!».

Rex piensa para sí: ¡Esto es bueno! Me gusta ser rey y gobernar tal como mi padre lo ha hecho. ¡Pero me gustaría tener la posibilidad de poder cambiar cualquier regla! Después de consultar al jurista de la corona, Rex decide promulgar una regla de preferencia llamada lex posterior $(! w)$ :

(t2) «iLex posterior priori derogat!».

Para comprobar que el sistema realmente funciona como él desea, Rex decide introducir el comunismo y proclama i (no- $p$ ) o ${ }^{*} p$ :

(t3) « ¿Lo que es mío es vuestro, queridos hermanos!».

Esta última decisión realmente no ayuda ni a la economía del reino de Rex ni a las relaciones sociales dentro de él, por lo que Rex decide restablecer el dominium plenum !(no-p):

(t4) « No codiciarás la casa de tu prójimo! ¡No codiciarás a la mujer de tu prójimo, ni a su sirviente o sirvienta, su buey, su asno, o cualquier otra cosa que le pertenezca!».

Por supuesto, estas traducciones del lenguaje natural a $p$ y no- $p$ son excesivamente simplificadas. Pero si la representación formal de $w$ dada más arriba es correcta, debemos poder mostrar lo que aquí es importante: primero, que la intervención legislativa ¡(no- $p$ ) en (t3) eliminó a no- $p$ del sistema normativo $\operatorname{Cn}(A)$; y segundo, que la intervención !(no- $p$ ) en (t4) reintrodujo a no- $p$ en el sistema $\operatorname{Cn}(A)$.

En (t1) tenemos los siguientes conjuntos:

(análisis ockhamita) $\quad A_{1}=\{$ no- $p\}, D_{1}=\{\varnothing\}$

(análisis moritziano) $\quad A_{1}=\{$ no- $p\}, D_{1}=\{\varnothing\}, P_{1}=\{\varnothing\}$ 
Nuestro sistema normativo $\operatorname{Cn}(A)$ contiene todas las consecuencias lógicas de no- $p$ y $w$.

Como resultado de la promulgación de Rex de ! $w$ en (t2), tenemos:

(análisis ockhamita) $\quad A_{2}=\{$ no- $p, w\}, D_{2}=\{\varnothing\}$

(análisis moritziano) $\quad A_{2}=\{$ no- $p, w\}, D_{2}=\{\varnothing\}, P_{2}=\{\varnothing\}$

y el sistema normativo $\operatorname{Cn}\left(A_{2}\right)$ contiene todas las consecuencias lógicas de no- $p$ y $w$.

La segunda ley de Rex en ( $\mathrm{t} 3$ ) puede ser representada como $i($ no- $p$ ) o, alternativamente, como * ${ }^{*}$. Esta intervención legislativa genera:

(análisis ockhamita) $\quad A_{3}=\{$ no- $p, w\}, D_{3}=\{$ no- $p\}$

(análisis moritziano) $\quad A_{3}=\{$ no- $p, w\}, D_{3}=\{\varnothing\}, P_{3}=\{p\}$

y un sistema normativo $\operatorname{Cn}\left(A_{3}\right)$ con todas las consecuencias lógicas de no- $p$ y $w$. Como se puede ver, tenemos un conflicto de ambivalencia con respecto a $p^{33}$, debido a la intersección de $\operatorname{Cn}\left(A_{3}\right)$ y $D_{3}$ o, dicho de otra forma, porque el conjunto de los elementos que pertenecen a ambos $\operatorname{Cn}\left(A_{3}\right)$ y $D_{3}$ es $\{$ no- $p\}$ y no un conjunto vacío.

A partir de ahora, no haré más representaciones con los elementos de $P$ en lugar de los de $D$, ya que si logramos dar una descripción adecuada de cómo funcionan las reglas de preferencia, sin admitir la existencia del acto normativo especial de otorgar un permiso, entonces sin duda podríamos tener éxito también en el otro caso (es decir, el análisis moritziano). Dicho esto, podemos dar un paso más y demostrar cómo la presencia de $w$ en el conjunto ordenado resuelve, de hecho, el conflicto.

En función de $w$, el conflicto se resuelve a favor de permitido $p$, lo que nos deja con los siguientes conjuntos:

(análisis ockhamita) $\quad A_{4}=\{w\}, D_{4}=\{$ no- $p\}$

y el sistema normativo $\operatorname{Cn}\left(A_{4}\right)$ con todas las consecuencias lógicas de $w$ y sin no- $p$ o sus consecuencias lógicas.

Aquí presento una prueba formal para el caso de $\operatorname{Cn}\left(A_{4}\right)$ :
Prueba 1
(1) $A_{2}=\{$ no- $p\}$
- Descripción de hechos.
(2) $A_{3}=\{$ no- $p, w\}$
- Descripción de bechos.
(3) $A_{\mathrm{i}} \subseteq \operatorname{Cn}\left(A_{\mathrm{i}}\right)$
- Def. 1 de $\operatorname{Cn}(\mathrm{A})$.
(4) no- $p \in \operatorname{Cn}\left(A_{2}\right) \wedge$ no- $p \in \operatorname{Cn}\left(A_{3}\right)$
- 1,2 ; conjunción; 3 .
(5) $D_{2}=\{\varnothing\}$
- Descripción de bechos.
(6) $D 3=\{$ no-p $\}$
- Descripción de bechos.
(7) no-p $\notin D 2 \wedge$ no-p $\in D 3$
- 5,6; conjunción.
(8) $\forall x\left[\left(x \notin D_{n-1} \wedge x \in D_{n}\right) \vee\left(\right.\right.$ no- $x \notin P_{n-1} \wedge$ no- $\left.x \in P_{n}\right) \wedge\left(x \in \mathrm{C}_{n}\left(A_{n-1}\right)\right.$ $\left.\wedge x \in \mathrm{C}_{n}\left(A_{n}\right)\right) \Rightarrow\left(D_{n+1}=D_{n}\right) \vee\left(P_{n+1}=P_{n}\right) \wedge\left(\mathrm{C}_{n}\left(A_{n+1}\right)=\mathrm{C}_{n}\left(A_{n}\right) \backslash\right.$ $\left.\{x\}) \wedge\left(A_{n+1}=A_{n} \backslash\{x\}\right)\right] \wedge\left[\left(x \in D_{n-1} \wedge x \in D_{n}\right) \vee\left(\right.\right.$ no $-x \in P_{n-1} \wedge$ no- $x$ $\left.\in P_{n}\right) \wedge\left(x \notin \mathrm{C}_{n}\left(A_{n-1}\right) \wedge x \in \mathrm{C}_{n}\left(A_{n}\right)\right) \Rightarrow\left(D_{n+1}=\left(D_{n} \backslash\{x\}\right)\right) \vee\left(P_{n+1}=\right.$ $\left(P_{n} \backslash\{\right.$ no- $\left.\left.\left.x\}\right)\right) \wedge\left(\mathrm{C}_{n}\left(A_{n+1}\right)=\mathrm{C}_{n}\left(A_{n}\right)\right) \wedge\left(A_{n+1}=A_{n}\right)\right] \wedge\left[\left(x \notin \mathrm{C}_{n}\left(A_{n-1}\right)\right.\right.$

${ }_{33}$ Hay un conflicto de ambivalencia $[\operatorname{Cn}(A), D]$, cuando existe al menos un $x$ tal que $x$ pertenece al conjunto $\operatorname{Cn}(A)$ y $x$ también pertenece al conjunto $D$. La intersección de $\operatorname{Cn}(A)$ con $D$ no es un conjunto vacío. Vid. las definiciones 13 y 14 en el apartado 3.1. 
$\left.\wedge x \in \mathrm{C}_{n}\left(A_{n}\right)\right) \wedge\left(\right.$ no- $x \in \mathrm{C}_{n}\left(A_{n-1}\right) \wedge$ no- $\left.x \in \mathrm{C}_{n}\left(A_{n}\right)\right) \Rightarrow\left(\mathrm{C}_{n}\left(A_{n+1}\right)=\right.$ $\left(\mathrm{C}_{n}\left(A_{n}\right) \backslash\{\right.$ no- $\left.x\}\right) \wedge\left(A_{n+1}=\left(A_{n} \backslash\{\right.\right.$ no- $\left.\left.\left.\left.x\}\right)\right)\right)\right] \wedge\left[\left(\left(x \in \mathrm{C}_{n}\left(A_{n-1}\right) \wedge x \in\right.\right.\right.$ $\left.\mathrm{C}_{n}\left(A_{n}\right)\right) \wedge\left(\right.$ no- $x \notin \mathrm{C}_{n}\left(A_{n-1}\right) \wedge$ no- $\left.x \in \mathrm{C}_{n}\left(A_{n}\right)\right) \Rightarrow\left(\mathrm{C}_{n}\left(A_{n+1}\right)=\left(\mathrm{C}_{n}\left(A_{n}\right)\right.\right.$ $\left.\backslash\{x\}) \wedge\left(A_{n+1}=\left(A_{n} \backslash\{x\}\right)\right)\right]$.

- 2; sustitución de $w$ por su def. 19.

(9) $($ no-p $\notin D 2 \wedge$ no-p $\in D 3) \wedge\left(\right.$ no-p $\in \mathrm{C}_{\mathrm{n}}(A 2) \wedge$ no-p $\left.\in \mathrm{C}_{\mathrm{n}}(A 3)\right) \Rightarrow$ $\left(\mathrm{C}_{\mathrm{n}}(A 4)=\left(\mathrm{C}_{\mathrm{n}}(A 3) \backslash\{\right.\right.$ no-p $\left.\left.\}\right)\right)$.

- 8; simplificación, determinación del indice $(\mathrm{n}=3)$ y la variable $(x$ $=$ no- $p$ ).

$$
\therefore \mathrm{C}_{\mathrm{n}}\left(A_{4}\right)=\left(\mathrm{C}_{\mathrm{n}}\left(A_{3}\right) \backslash\{\text { no- } p\}\right)
$$

- 9, 7, 4; modus ponens.

Las pruebas formales para $A_{4}$ y $D_{4}$ reiteran la prueba para $\operatorname{Cn}\left(A_{4}\right)$ desde los pasos 1 a 8 ; en este punto, saltaré el obvio paso 9 para alcanzar las conclusiones $\left(D_{4}=D_{3}=\right.$ $\{$ no- $p\}$ y $A_{4}=\left(A_{3} \backslash\{\right.$ no- $\left.\left.p\}\right)=\{w\}\right)$ vía modus ponens. El argumento para el análisis moritziano $\left(A_{4}=\{w\}, D_{4}=\{\varnothing\}, P_{4}=\{p\}\right)$ es muy similar y también fácil.

Como vemos, la presencia de $w$ en el conjunto ordenado $A$ tiene el efecto esperado: garantizó la prioridad de la segunda ley de Rex del momento (t3), como un acto normativo posterior, sobre la previa ley del Rex-padre procedente de (t1). Además, podríamos mostrar que $w$ también garantiza el resultado deseado en caso de la intervención legislativa subsecuente de Rex en (t4), pero esto ya parece innecesario - puesto que ahora cada uno puede hacerlo por sí mismo transitando (casi) el mismo argumento. Este mostraría que la promulgación de no- $p$ en $(\mathrm{t} 4)$ produce un conflicto de ambivalencia; entonces se vería que, con base en lex posterior $(w)$, el conflicto se resuelve (esta vez) a favor de la prohibición no- $p$ - dejándonos con los siguientes conjuntos:

$$
\text { (análisis ockhamita) } \quad A_{6}=\{w, \text { no- } p\}, D_{6}=\{\varnothing\}
$$

y el sistema normativo $\operatorname{Cn}(A)$ que contiene todas las consecuencias lógicas de no- $p$ y $w$.

Finalmente podemos concluir que nuestro expresivista puede describir adecuadamente el funcionamiento de lex posterior sin dar contenido semántico al indicador de fuerza (normativa). QED.

En un comentario al manuscrito de este trabajo, ŽARNIĆ y BAŠIć (2014: párr. 2.2) mostraron que la definición 19 de lex posterior funciona sólo en un número limitado de casos especiales (tales como el de nuestro ejemplo) donde el conjunto normativo inicial es independiente, es decir, donde ningún miembro del conjunto normativo inicial puede derivarse de los demás miembros del mismo. Con gusto concedo el punto y reconozco mi error (como uno puede observar desde la cita de más arriba acompañada por la nota al pie núm. 25, ALCHOURRÓn y BulYGIN fueron mucho más cuidadosos que yo en su explicación de las consecuencias de un acto de rechazo). Si $x$ acaba de ser rechazado (o no- $x$ permitido), siendo miembro del sistema normativo $\operatorname{Cn}(A)$, entonces de la operación de derogación resultan nuevos conjuntos $A$ y $\operatorname{Cn}(A)$ que son —a diferencia de lo expuesto en la definición 19- subconjuntos máximos de los conjuntos anteriores que no implican formalmente $x$. Esto significa que «la operación de derogación es infradeterminada, puesto que, típicamente, hay más de un subconjunto máximo» de 
$A$ y $\operatorname{Cn}(A)$ que no implica formalmente $x$. En tales casos, «quien aplique el derecho se verá obligado a elegir entre estos subconjuntos máximos» $\mathrm{y}$ asumir el papel del creador del derecho. La representación de esta operación, entonces, «necesita un operador adicional de elección» para elegir uno de tales subconjuntos ${ }^{34}$. Puesto que el exacto contenido proposicional de lex posterior no está en el alcance de esta contribución, no voy a enmendar aquí la definición 19 como debería, sino que lo dejo para otra ocasión (o para el lector interesado, ahora).

En favor de la claridad (y brevedad) de la demostración he asumido que lex posterior es la única regla de preferencia en el reino de Rex. Sin embargo, debo al menos una pista para la solución correspondiente a la regla de preferencia lex superior derogat inferiori $(! s)^{35}$ : supondremos que los contenidos que fueron promulgados y rechazados (o permitidos) vayan en diferentes subconjuntos de los conjuntos $A$ y $D$ (o $P)$ - por ejemplo, en $A \mathrm{a}, A \mathrm{~b}, A \mathrm{c}$, etc.- dependiendo del nivel jerárquico ( $\mathrm{a}, \mathrm{b}, \mathrm{c}$, etc.) de la autoridad normativa que realiza el acto normativo en cuestión. Con el uso de estos subconjuntos, uno debería poder formular sin problemas el contenido proposicional $s$ de lex superior $(! s)$.

Cabe ahora enfrentarse a una última serie de objeciones.

\section{LA REGLA DE CLAUSURA Y OTRAS NORMAS CONDICIONALES}

Antes de concluir con una posible representación de las normas condicionales, veamos el problema de la regla de clausura.

5.1. Es ampliamente conocido ${ }^{36}$ que la «regla permisiva de clausura» («Aquello que no está prohibido, está permitido») es la única regla de clausura que no deja abierta la entrada a incoherencias dentro de un sistema normativo ${ }^{37}$. CALZETTA y SARDO (2014) reivindican esta idea en contra del análisis ockhamita, en el sentido de que un expresivista ockhamita (por el hecho de negar la existencia de normas permisivas o actos de permitir) no podría dar cuenta de dicha regla de clausura ${ }^{38}$. Pero dicha acusación es falsa o, en el mejor de los casos, inaplicable y fruto de un malentendido.

Una cosa es decir que a) con el propósito de preservar la coherencia, un sistema normativo puede ser completado con una regla de clausura sólo si dicha regla tiene el efecto de permitir lo que no está prohibido. Otra cosa muy diferente es decir que $b$ ) solamente una norma permisiva de clausura tendría este efecto o carácter permisivo,

34 ŽARnIĆ y BAŠIĆ, 2014, párr. 2.2. Vid. también ALCHOURRÓN y BuLYGIN, 1991a: 139-140.

35 La tercera regla de preferencia, lex specialis, no genera las preocupaciones expresadas por WEINBERGER (1985) y por CALZETTA y SARDo (2014). Vid. también ALCHOURRÓn y BulYgin, 1979: 86.

36 Para la discusión al respecto vid. ALChOuRRón y BuLYgin, 1971/1975: Cap. 7, y las referencias allí incorporadas.

37 Con la sola excepción, prácticamente irrelevante, de un sistema normativo en el cual se infiera que $p$ no es facultativo $(\neg \mathrm{I} p=\neg(\mathrm{P} p \wedge \mathrm{P}($ no- $p)))$. «Como $p$ no está prohibido, podríamos inferir con la ayuda de la [permisiva] regla de clausura que $p$ está permitido. Pero, como tampoco está prohibido no- $p$, se podría inferir también la permisión de no- $p$. Sin embargo, la permisión conjunta de $p$ y no- $p$ es incompatible con $\neg[I] p$. He aquí, pues, que la regla de clausura ha introducido una incoherencia». ALCHOURRÓn y BULYGIN, 1975: 195, n. 41.

38 Vid. CALZETTA y SARDO, 2014: párr. 2.1.2. 
esta función normativa. Mientras $a$ ) es verdadero, pero no es lesivo (el expresivista ockhamita también reconoce la existencia de estados de cosas permitidos) ${ }^{39}, b$ ) es falso, ya que el rechazo de la prohibición de $p$ cumple la misma función permisiva que la permisión de $p$. He aquí una prueba de ello:

Supongamos que Rex decide clausurar el sistema de su reino y dicta la siguiente regla de clausura permisiva $(! c)^{40}$ :

(t5) «Aquello que no está prohibido, está permitido!».

El contenido proposicional $c$, que así pasa a ser un elemento de $A$, puede formalizarse de la siguiente forma:

Def. 20 Regla de clausura permisiva (c):

$\forall x\left(\right.$ no- $x \notin \operatorname{Cn}\left(A_{n}\right) \Rightarrow$ no- $\left.x \in D_{n+1}\right)$.

Para todo $x$, si $x$ no está prohibido - esto es, si no- $x$ no pertenece al sistema normativo $\operatorname{Cn}\left(A_{n}\right)$ - entonces no- $x$ pertenece al conjunto rechazado $D_{n+1}$.

Presentado de esta forma, !c obtiene los resultados deseados de una clausura permisiva: i) No tiene un efecto (directo) sobre destinatarios particulares de las normas; la introducción de tal regla de clausura no afecta la calificación deóntica de conductas individuales. ii) $\mathrm{Al}$ hacer que $p$ esté positivamente permitido, !c elimina lagunas normativas y, por ende, la discreción judicial en casos de $p$ (relativos al sistema normativo de $A$ ). iii) Como la adición de no- $p$ al conjunto derogado $D$ es condicional, actos futuros de rechazo explícito no pierden su relevancia, como veremos en breve, y iv) incluso pueden ser realizados por autoridades subordinadas a aquella autoridad que promulgó $c$.

A quienes se mantengan escépticos acerca de los puntos iii) y iv), he de requerirles entonces una pizca más de paciencia con el ejercicio lógico a los fines de una última simulación; los demás pueden saltarse los próximos cuatro párrafos.

Supongamos que la base axiomática se compone de las normas constitucionales $\{a, c, s, w\}$ y que no- $x \notin \operatorname{Cn}\left(A_{1}\right)$. En consecuencia, no- $x \in D_{2}$ en función de la regla (condicional) de clausura permisiva $c$ (o sea: si está prohibido $x$ en $\operatorname{Cn}\left(A_{n}\right)$, entonces no- $x$ pertenece a $\left.D_{n+1}\right)^{41}$. Además, $A_{1}=A_{2}$ y no- $x \notin \mathrm{Cn}\left(A_{2}\right)$, lo cual significa que $x$ está permitido positivamente ${ }^{42}$.

Ahora bien, imaginemos dos escenarios diferentes. En el primer escenario, el ayuntamiento de una ciudad ordena $b$, que tiene el contenido $(a \Rightarrow$ no- $x$ ). Como consecuencia de $! b$, tenemos $A_{3}=\{a, b, c, s, w\}$ y no- $x \in \operatorname{Cn}\left(A_{3}\right)$-lo cual produce un conflicto de ambivalencia entre $\operatorname{Cn}\left(A_{3}\right)$ y $D_{3}\left(=D_{2}\right)$ - El conflicto puede ser resuelto mediante la aplicación de lex posterior $(w)^{43}$, de suerte que resulta: $D_{4}=\left(D_{3} \backslash\right.$ no- $\left.x\right)$, mientras

39 Alchourrón y Bulygin, 1991a: 146.

40 Para evitar la ambigüedad de la expresión «regla permisiva de clausura» —en la que el adjetivo «permisiva» puede ser utilizado tanto para especificar la función de la regla, como para especificar la forma de la regla o ambas-, he escogido usar el término en cuestión sólo en el segundo sentido (haciendo referencia a la forma), y expresar el primer sentido (el de la función) utilizando «regla de clausura permisiva».

41 Vid. más arriba la definición 20 en este apartado.

42 Para todo $p$, «p está permitido de forma positiva en $A \gg$ es verdadera si, y sólo si, no- $p$ forma parte del conjunto rechazado $D$. Vid. más arriba la definición 11 en el apartado 2.

43 Vid. más arriba la definición 19 en el apartado 4. 
que $A_{4}=A_{3}$ y no- $x \in \operatorname{Cn}\left(A_{4}\right)$. En otras palabras: $x$ queda prohibido como consecuencia de que el ayuntamiento de la ciudad ordena $b$, aun cuando hasta ahora había sido permitido positivamente debido a la presencia de la regla (constitucional) de clausura permisiva $c$. Nótese que la regla lex superior $(s)$ no desempeña ningún papel en la resolución de este conflicto entre normas.

Ahora imaginemos otro escenario en el cual no- $x$ es (incondicionalmente) rechazada por el legislador nacional antes de que el ayuntamiento de la ciudad ordene $b$. En consecuencia, no- $x \in D_{3}$, mientras que $A_{3}=A_{2}=A_{1}$ y no- $x \notin \mathrm{Cn}\left(A_{3}\right)$. Esto también significa que $x$ está permitido positivamente. Sin embargo, las consecuencias de emitir la orden $b$ por parte del ayuntamiento de la ciudad serán diferentes en este escenario. El conflicto de ambivalencia se resolverá aplicando lex superior $(s)$ y no lex posterior $(w)$. Se dará preferencia al rechazo de no- $x$. Como consecuencia, $x$ no será prohibido, sino que se mantendrá permitido positivamente.

Las últimas dos simulaciones demuestran: iii) que actos futuros de rechazo explícito no pierden su relevancia bajo la regla de clausura permisiva $c$ con la formalización arriba mostrada - del mismo modo en que dichos actos tampoco pierden su relevancia en los sistemas jurídicos que contienen esta misma regla de clausura-; y iv) que los actos futuros de rechazo explícito pueden ser realizados por autoridades subordinadas a aquella que promulgó $c$.

No es éste el lugar para discutir en detalle las cuatro características de dicha clausura permisiva. Lo relevante es haber mostrado que la función permisiva de la regla de clausura, según la cual aquello que no está prohibido está permitido, puede ser debidamente representada sin conceder que existe un específico acto (normativo) elocutivo de permisión. QED.

5.2. Además, nuestro expresivista ockhamita ya ha puesto en marcha todas las herramientas necesarias para reconstruir las normas condicionales incluyendo la siguiente ${ }^{44}$ :

$\left(\mathbf{R}_{4}\right)$ «iSi, y sólo si, está lloviendo, no salgas de casa!».

Mientras quien defiende una concepción hilética representaría $\mathrm{R}_{4}$ como un imperativo condicional, nuestro expresivista echará mano de un conjunto más —aquel, denominémoslo el conjunto fáctico $F$, compuesto por las proposiciones que describen los hechos y acciones relevantes que acaecen en el contexto de aplicación de la regla-, para representar a $\mathrm{R}_{4}$ como un condicional imperativo o, más precisamente, como una orden de hacer verdadera la proposición condicional:

$$
\begin{array}{ll}
\left(\mathrm{R}_{4} \text { en su representación hilética }\right) & \mathrm{p} \Leftrightarrow \mathrm{O}(\text { no- } r)^{45} \\
\left(\mathrm{R}_{4} \text { en su representación expresivista }\right) & \left.!\left(p \in F_{n}\right) \Leftrightarrow\left(\text { no- } r \in A_{n+1}\right)\right)
\end{array}
$$

donde $p$ significa $<$ está lloviendo $>$ y $r<$ salir de casa $>$.

Uno podría preferir la primera representación o la segunda por razones de gusto (intelectual u otro). Pero, en cuanto a su capacidad instrumental, la representación expresivista proporciona lo necesario para asegurar los efectos que se esperan de $R_{4}$ :

\footnotetext{
44 El ejemplo proviene de Alchourrón y Bulygin, 1979: Cap. 8.

45 Algunos problemas de está representación están tratados en RODRÍGUEZ, 2005.
} 
si está lloviendo $(p)$, entonces existe la explícita prohibición de que salgas de casa. Si no está lloviendo (no- $p$ ), entonces existe un permiso negativo de (y, por ende, no es obligatorio) salir de casa ${ }^{46}$. Esto puede verificarse fácilmente, si acudimos a nuestras previas definiciones de prohibición explícita (def. 6) y de permiso negativo (def. 12) ${ }^{47}$.

Cuando se dicta $\mathrm{R}_{4}$, su contenido proposicional entra en la base axiomática $A_{n}$. En beneficio de la simplicidad supongamos que ésta es la única regla existente en el reino de Rex, que $D_{n}$ es un conjunto vacío y que $\operatorname{Cn}\left(A_{n}\right)$ contiene todas las consecuencias lógicas de $\mathrm{R}_{4}$. Ahora bien, si no está lloviendo, salir de casa $(r)$ está permitido negativamente $^{48}$, debido a que $D_{n}$ se mantiene vacío y $\operatorname{Cn}\left(A_{n}\right)$ no contiene quedarse en casa (no-r). Por otra parte, si el caso es que está lloviendo, existe la prohibición explícita de salir de casa ${ }^{49}$, debido a que no- $r$ pertenece a $A_{n+1}$.

Así es como uno podría refutar la objeción presentada por WEINBERGER (1985 y 1986) y finalmente concedida por ALCHOURRÓN y BULYGIN (1991): a saber, que un expresivista no puede dar una reconstrucción satisfactoria de las normas condicionales ${ }^{50}$.

Si el expresivista hace uso de i) secuencias de ii) distintos conjuntos (incluyendo el conjunto $F$ relativo a los hechos y acciones que acaecen en el contexto de aplicación) y si retrata a las normas condicionales no como imperativos condicionales, sino como iii) órdenes de hacer verdaderos los condicionales, entonces puede traducirse fácilmente la representación hilética de las normas condicionales (primera columna) a la representacion expresivista (segunda columna):
Def. 21 Si $p$, entonces $\mathrm{O} q$.
Def. 22 Si $p$, entonces $\mathrm{Ph} q$.
$!\left(\left(p \in F_{n}\right) \Rightarrow\left(q \in A_{n+1}\right)\right)$.
Def. $23 \mathrm{Si} p$, entonces $\mathrm{P} q$.
$!\left(\left(p \in F_{n}\right) \Rightarrow\left(\right.\right.$ no- $\left.\left.q \in A_{n+1}\right)\right)$.
$!\left(\left(p \in F_{n}\right) \Rightarrow\left(\right.\right.$ no- $\left.\left.q \in D_{n+1}\right)\right)$.

Por cierto, algunos dirán que el precio que hay que pagar es demasiado alto — puesto que, ahora, nuestra base axiomática y, por ende, nuestro sistema normativo cambiarán junto con las condiciones climáticas y otras circunstancias fácticas más allá e independientemente de las órdenes y derogaciones- ${ }^{51}$. Pero hay al menos dos modos de evitar el problema.

a) A partir de la regla general $\mathrm{R}_{4}$ ( $\ll_{i} \mathrm{Si}$, y sólo si, está lloviendo, no salgas de casa!») y del hecho $p$ (está lloviendo), deseamos obtener como consecuencia la obligación de quedarse en casa. Pero esto puede interpretarse como una obligación individual en el caso particular que tenemos a mano. Esta obligación se deriva de una norma general (o de su contenido proposicional) y de una premisa fáctica. Ahora bien,

46 Vid. AlchourRón y Bulygin, 1979: Cap. 8, cuya tentativa representación de las reglas condicionales no logra responder a estas exigencias.

${ }_{47}$ Las definiciones se han introducido en el apartado 2 y se van a repetir en el párrafo siguiente.

48 Para todo $x$, «x está permitido de forma negativa en $A \gg$ es verdadera si, y sólo si, no- $x$ no pertenece ni al conjunto $\operatorname{Cn}(A)$ ni al conjunto rechazado $D$. Vid. la definición 12, en el apartado 2 .

${ }_{49}$ Para todo $x$, «x está explícitamente prohibido en $A \gg$ es verdadera si y sólo si no- $x$ pertenece al conjunto A. Vid. la definición 6, en el apartado 2.

50 Vid. WeinBerger, 1985: 175 y ss. Vid. también AlchourRón y Bulygin, 1991: xxvii, y en especial CARACCIOLO, 1993: 507.

${ }^{51}$ De hecho, para algunos la idea misma de sistema normativo sólo es de interés si éste no cambia junto con las circunstancias fácticas (excepto las que constituyen los actos normativos de promulgación y derogación). Agradezco a José Juan MoRESO por haber llamado mi atención sobre este punto. 
si tomamos tales obligaciones individuales no como partes del sistema normativo, sino como aplicaciones de sus contenidos a circunstancias fácticas, entonces podemos preservar la independencia del sistema normativo respecto de los hechos siempre cambiantes: en vez de ubicar a no-r (o sea, quedarse en casa) en la base axiomática $A_{n+1}$, simplemente debemos ubicarlo en un conjunto separado de obligaciones individuales del caso particular que se está discutiendo; llamamos a este conjunto $I_{n+1}$. $\mathrm{R}_{4}$ deberá entonces representarse como $!\left(\left(p \in F_{n}\right) \Leftrightarrow\left(\right.\right.$ no- $\left.\left.r \in I_{n+1}\right)\right)$. En consecuencia también se deberán modificar las definiciones dadas arriba acerca de qué es obligatorio, qué está prohibido y qué permitido (def. 2-def. 12); pero ello no podrá socavar la afirmación de que el expresivista puede representar adecuadamente las normas condicionales.

b) Otro modo de evitar el supuesto problema del cambio excesivamente frecuente del sistema normativo consiste en identificar el sistema normativo con el conjunto ordenado $A$ y no con el conjunto $\operatorname{Cn}(A)$ que incluye todas las consecuencias lógicas de las proposiciones explícitamente ordenadas. Uno podría quedarse entonces con la representación inicialmente propuesta de las normas condicionales (def. 21-def. 23) y con la idea de que los sistemas normativos no cambian junto con las circunstancias fácticas (excepto las que constituyen los actos de promulgación y derogación). Esta solución también está en consonancia con las objeciones que ŽARNIĆ y BAŠIĆ (2014) levantaron contra mi adopción de la definición usual de sistema normativo (o sea, la que incluye la clausura deductiva). Sus argumentos me parecen convincentes y aunque no voy a citarlos aquí - ya que no van en contra de la concepción expresiva como tal - podemos concluir conectando su propuesta (general) con nuestro tema (especial) de las normas condicionales: quien aplica el derecho realiza una deducción desde la regla general $\mathrm{R}_{4}$ («iSi, y sólo si, está lloviendo, no salgas de casa!») y el hecho $p$ (está lloviendo); sin embargo, no hay «ningún conjunto $\operatorname{Cn}(A)$ deductivamente cerrado que necesite preceder o pueda ser el resultado de la así obtenida determinación del estatus deóntico del estado de cosas producido por una acción del sujeto del derecho o por su omisión» (ŽARNIĆ y BAŠIĆ, 2014: párr. 2.1). La relación entre $\mathrm{R}_{4}$ y la obligación individual (en el caso de lluvia) o el permiso individual (en todas las demás circunstancias) tiene que ver con el razonamiento que uno realiza por medio de enunciados normativos. En otras palabras, las reglas de inferencia que nos hacen derivar las normas implícitas y/o individuales de las explícitas y generales definen el contexto metanormativo para el aplicador del derecho y no tienen ninguna relación necesaria con el sistema normativo por sí mismo ${ }^{52}$. Bajo esta visión, desaparece el problema del cambio excesivamente frecuente del sistema normativo.

Por supuesto, la concepción expresiva de las normas (y, especialmente, su variante ockhamita) puede tener otras imperfecciones e incluso algún problema serio ${ }^{53}$. Pero si

52 Vid. ŽARNIĆ y BAŠIĆ, 2014: en particular párrs. 1.1 y 2.1, refiriéndose también a John BROOME, Lou GOBLE y Jürgen HABERMAS.

53 No tomaré posición a este respecto, solamente quisiera indicar algunas lecturas adicionales. Aunque ya mencionado, WEINBERGER, 1985 y 1986, es el mejor punto de partida, puesto que se extiende también a varios temas no tratados en este texto. El argumento de OPAŁEK y WOLEŃSKI, 1986, 1987/2014 y 1991, va en contra de la concepción expresivista de los permisos. NAVARRO y REDONDO, 1990b: 238 y ss., señalan algunas cuestiones relativas al conjunto rechazado (y sus subconjuntos) por traer problemas a las explicaciones de AlCHOURRÓn y Bulygin. Moreso y NAVARRO, 1992: 1089, pretenden mostrar una ambigüedad en la permisión positiva. AGUILÓ, 1995: 59 y ss.; 63 y ss., invoca un problema respecto de la derogación (tácita o) por incompatibilidad. CARACCIOLO, 1996: nn. 15, 25 y 31, muestra el problema de la identificación de los sistemas 
las demostraciones señaladas en este trabajo son correctas, el expresivista de ALCHOURRÓN y BULYGIN (1981/1991) puede perfectamente dar cuenta de estados de cosas fa-

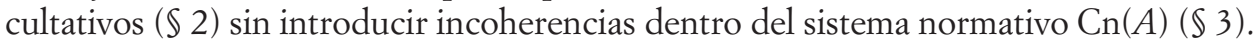
Su expresivista también puede describir con éxito el contenido proposicional de una metarregla sin dotar de contenido semántico al indicador de fuerza (normativa) de la regla-objeto $(\$ 4)$. Y por último, puede dar cuenta de una clausura permisiva -y de otras normas condicionales- aun cuando niegue la autonomía conceptual de actos de permisión o, en palabras diferentes, su irreducibilidad a otras formas normativas $(\$ 5)$.

Agradecimientos. Quería agradecer a Alejandro CALZETTA y Alessio SARDO por las largas y vivas discusiones sobre el tema, así como a Eugenio BulYGin, Damiano CANALe, Diego Dei Vecchi, Alessandro Ferrari, Pablo Rapetti, Giovanni Battista Ratti, Sebastián Figueroa, José Juan Moreso, Pablo Navarro, Cristina Redondo y Jan WOLEŃSKI por sus comentarios acerca de varias partes del borrador. Me he beneficiado, además, de dos informes evaluativos negativos: mientras que un revisor anónimo de Doxa consideró erróneas mis formalizaciones lógicas, otro revisor de Studia Logica consideró las mismas, en su mayoría, simples y obvias hasta el punto de constituir una contribución trivial. En última instancia, he decidido efectuar sólo algunas pequeñas correcciones a mis formulaciones lógicas respecto a la versión original. Tengo la impresión de que el resultado no debería suscitar mayor interés entre los lógicos, pero sí entre los teóricos del derecho.

\section{BIBLIOGRAFÍA}

Aguiló, J., 1995: Sobre la derogación. Ensayo de dinámica jurídica, México: Fontamara (Biblioteca de ética, filosofía del derecho y política, 41).

Alchourrón, C. E., y Bulygin, E., 1971: Normative Systems, Wien/New York: Springer (Library of Exact Philosophy, 5).

- 1975: Introducción a la metodología de las ciencias jurídicas y sociales, Buenos Aires: Astrea (Colección mayor Filosofía y Derecho, 1).

- 1979: Sobre la existencia de las normas jurídicas, Valencia (Venezuela): Universidad de Carabobo. Cité las páginas de la reimpresión en México: Fontamara, 1997.

- 1981: «The Expressive Conception of Norms», en R. Hilpinen (dir.), New Studies in Deontic Logic, Dordrecht: Reidel, 95-124. Reimprimido en B. LitsChEWSKI-PAULSON y S. PAulSON (dirs.), Normativity and Norms, Oxford: Oxford University Press, 1998, 384-410.

— 1984: «Pragmatic Foundations for a Logic of Norms», Rechtstheorie, 15: 453-464.

- 1991: Análisis lógico y Derecho, Madrid: Centro de Estudios Constitucionales.

- 1991a: «La concepción expresiva de las normas», en C. E. AlCHOURRÓn y E. BulYgin, Análisis lógico y Derecho, Madrid: Centro de Estudios Constitucionales, 121-153.

- 1991b: «Fundamentos pragmáticos para una lógica de normas», en C. E. ALCHOURRÓn y E. Bulygin, Análisis lógico y Derecho, Madrid: Centro de Estudios Constitucionales, 155-167.

CALZETTA, A. D., y SARDO, A., 2014: «Una nueva visita a la concepción expresiva de las normas», Doxa. Cuadernos de Filosofía del Derecho, 37.

normativos de la concepción expresivista con el derecho. Por último, se puede consultar FERRER BeLTRÁn y RoDRíGUEZ, 2011: Cap. 1, donde los autores alegan la existencia de dos concepciones acerca del significado y no acerca de las normas. 
Caracciolo, R., 1993: «Entrevista a Eugenio Bulygin», Doxa. Cuadernos de Filosofía del Derecho, 14: 499-513.

- 1996: «Esistenza di norme e di sistemi normativi», en P. COMANDUCCI y R. GUASTINI (dirs.), Struttura e Dinamica dei Sistemi Giuridici, Torino: Giappicheli Editore. En español: «Existencia de normas», Isonomía. Revista de teoría y Filosofía del Derecho, 7: 159-178. Reimprimido en R. CARACCIOLO, El Derecho desde la filosofía, Madrid: Centro de Estudios Políticos y Constitucionales (El Derecho y la Justicia), 2009.

FERRER BeltrÁn, J., y RodrígueZ, J. L., 2011: Jerarquías normativas y dinámica de los sistemas jurídicos, Madrid: Marcial Pons (Filosofía y Derecho).

Moritz, M., 1963: «Permissive Sätze, Erlaubnissätze und deontische Logik», en A. AHLBERG, R. EKMAN et al., Philosophical Essays Dedicated to Gunnar Aspelin on the Occasion of His Sixty-fifth Birthday, Lund: Gleerups, 108-121.

NAVARRO, P. E., y Moreso, J. J., 1992: «Normas permisivas, sistemas jurídicos y clausura normativa. Un análisis de la evolución de las ideas de Carlos Alchourrón y Eugenio Bulygin», Theoría. Revista de Teoría, Historia y Fundamentos de la Ciencia, Segunda época, vol. 7, núms. 16-17-18, t. B: 1079-1100.

Navarro, P. E., y Redondo, M. C., 1990a: «Permisiones y actitudes normativas», Doxa. Cuadernos de Filosofía del Derecho, 7: 249-255.

- 1990b: «Derogations, Logical Indeterminacy and Legal Expressivism», Rechtstheorie, 21: 233-239.

OpaleK, K., y WoleńsKi, J., 1986: «On Weak and Strong Permissions Once More», Rechtstheorie, $17:$ : 83-88.

- 1987: «Is, Ought, and Logic», Archiv für Rechts- und Sozialphilosophie, LXXIII: 373-385.

- 1991: «Normative Systems, Permissions, and Deontic Logic», Ratio Juris, 4: 334-348.

- 2014: «Ser, deber ser y lógica», Revus. Journal for Constitutional Theory and Philosophy of Law, 23. URL = bttp://revus.revues.org/2979.

RODRÍGUEZ, J. L., 2005: «Un dilema en la representación de normas condicionales», Isonomía. Revista de Teoría y Filosofía del Derecho, 23: 97-114.

Weinberger, O., 1985: «The Expressive Conception of Norms: An Impasse for the Logic of Norms», Law and Philosophy, 4: 165-198. Reimprimido en B. LiTSCHEWSKI-PAULSON y S. PAulson (dirs.), Normativity and Norms, Oxford: Oxford University Press, 1998: 411-432.

- 1986: «Der normenlogische Skeptizismus», Rechtstheorie, 17: 13-81.

ŽARnić, B., y BAŠIć, G., 2014: «Metanormative Principles and Norm Governed Social Interaction», Revus. Journal for Constitutional Theory and Philosopby of Law, 22: 105-120. $\mathrm{URL}=$ bttp://revus.revues.org $/ 2859$. 